\title{
Intranasal Dexamethasone: a New Clinical Trial For The Control of Inflammation and Neuroinflammation in Covid-19 Patients
}

\section{Graciela Caádenas}

Instituto Nacional de Neurología y Neurocirugía Manuel Velasco Suárez: Instituto Nacional de Neurologia y Neurocirugia Manuel Velasco Suarez

\section{Ana María Espinosa}

Hospital General de Mexico Dr Eduardo Liceaga

\section{María Chavez-Canales}

Instituto Nacional de Cardiología Ignacio Chávez: Instituto Nacional de Cardiologia Ignacio Chavez

\section{Antonio Jordán-Ríos}

Instituto Nacional de Cardiología Ignacio Chávez: Instituto Nacional de Cardiologia Ignacio Chavez

\section{Daniel Anica Malagon}

Hospital General de México Dr Eduardo Liceaga: Hospital General de Mexico Dr Eduardo Liceaga

\section{Manlio F. Márquez}

Instituto Nacional de Cardiología Ignacio Chávez: Instituto Nacional de Cardiologia Ignacio Chavez

\section{Laura Torres-Araujo}

Instituto Nacional de Cardiología Ignacio Chávez: Instituto Nacional de Cardiologia Ignacio Chavez

\section{Ricardo Barajas-Campos}

Instituto Nacional de Cardiología Ignacio Chávez: Instituto Nacional de Cardiologia Ignacio Chavez

\section{Rosa Wong}

UNAM Facultad de Medicina: Universidad Nacional Autonoma de Mexico Facultad de Medicina

\section{Luis Ramírez}

Unidad Temporal Citibanamex

\section{Karent lbet}

Unidad Temporal Citibanamex

\section{Enrique García}

Unidad temporal Citibanamex

\section{Mariana Rodriguez}

Unidad Temporal Citibanamex

\section{Yoana Leyva}

Instituto Nacional de Cardiología Ignacio Chávez: Instituto Nacional de Cardiologia Ignacio Chavez Joselin Hernández-Ruíz

Hospital General de México Dr Eduardo Liceaga: Hospital General de Mexico Dr Eduardo Liceaga 


\section{María Hernández-Mendel}

Hospital General de México Dr Eduardo Liceaga: Hospital General de Mexico Dr Eduardo Liceaga

\section{Mireya León-Hernández}

Hospital General de México Dr Eduardo Liceaga: Hospital General de Mexico Dr Eduardo Liceaga

\section{Karen Medina}

SEDENA: Mexico Secretaria de Defensa Nacional

\section{Anahi Sánchez}

SEDENA: Mexico Secretaria de Defensa Nacional

\section{Sergio Hernández}

SEDENA: Mexico Secretaria de Defensa Nacional

\section{Ignacia Zeron}

SEDENA: Mexico Secretaria de Defensa Nacional

\section{Adriana Martínez-Cuazitl}

SEDENA: Mexico Secretaria de Defensa Nacional

\section{Iván Martínez}

SEDENA: Mexico Secretaria de Defensa Nacional

\section{Eduardo Beltrán}

SEDENA: Mexico Secretaria de Defensa Nacional

\section{Aldo Figueroa}

SEDENA: Mexico Secretaria de Defensa Nacional

\section{Patricia Hernández}

SEDENA: Mexico Secretaria de Defensa Nacional

\section{Rafael I Aguilar}

SEDENA: Mexico Secretaria de Defensa Nacional

\section{Daniela Murillo-Reyes}

SEDENA: Mexico Secretaria de Defensa Nacional

\section{Luis R. Del Río}

SEDENA: Mexico Secretaria de Defensa Nacional

\section{Rogelio A. Alfaro-Bonilla}

SEDENA: Mexico Secretaria de Defensa Nacional

\section{Joselyn Cruz}

Instituto Nacional de Neurología y Neurocirugía Manuel Velasco Suárez: Instituto Nacional de Neurologia y Neurocirugia Manuel Velasco Suarez

\section{Leonor Huerta}

UNAM Instituto de Investigaciones Biomedicas: Universidad Nacional Autonoma de Mexico Instituto de Investigaciones Biomedicas

\section{Nora Fierro}

UNAM Instituto de Investigaciones Biomedicas: Universidad Nacional Autonoma de Mexico Instituto de Investigaciones Biomedicas 


\section{Marisela Hernández}

UNAM Instituto de Investigaciones Biomedicas: Universidad Nacional Autonoma de Mexico Instituto de Investigaciones Biomedicas

\section{Mayra Pérez-Tapia}

Unidad de desarrollo e investigación en Bioprocesos. ENCB-IPN

\section{Gabriela Meneses}

Insituto de diagnostico y referencia epidemiológicos

\section{Helgi Jung}

UNAM Facultad de Quimica: Universidad Nacional Autonoma de Mexico Facultad de Quimica

\section{Erick Espíndola-Arriaga}

UNAM Instituto de Investigaciones Biomedicas: Universidad Nacional Autonoma de Mexico Instituto de Investigaciones Biomedicas

\section{Gabriela Rosas}

Universidad Autónoma del Estado de Morelos Facultad de Medicina: Universidad Autonoma del Estado de Morelos Facultad de Medicina

\section{Roxana Olguin}

UNAM Instituto de Investigaciones Biomedicas: Universidad Nacional Autonoma de Mexico Instituto de Investigaciones Biomedicas

\section{Sandra Ortega}

UNAM Instituto de Investigaciones Biomedicas: Universidad Nacional Autonoma de Mexico Instituto de Investigaciones Biomedicas

\section{Alberto Chinney}

Unidad Temporal Citibanamex

\section{Sergio Rosales}

Universidad Autónoma de San Luis Potosí: Universidad Autonoma de San Luis Potosi

\section{Juan Hernández-Aceves}

UNAM Instituto de Investigaciones Biomedicas: Universidad Nacional Autonoma de Mexico Instituto de Investigaciones Biomedicas

\section{Jaquelynne Cervantes-Torres}

UNAM Instituto de Investigaciones Biomedicas: Universidad Nacional Autonoma de Mexico Instituto de Investigaciones Biomedicas

\section{Hugo Besedovsky}

Institute of Physiology and Pathophysiology. Emil- MannKopff- StraBe

\section{Marta C. Romano}

CINVESTAV Departamento de Fisiologia Biofisica y Neurociencias

\section{Raúl J Bobes}

UNAM Instituto de Investigaciones Biomedicas: Universidad Nacional Autonoma de Mexico Instituto de Investigaciones Biomedicas

\section{Gloria Soldevila}


UNAM Instituto de Investigaciones Biomedicas: Universidad Nacional Autonoma de Mexico Instituto de Investigaciones Biomedicas

\section{Juan Lopez}

University of Texas at Brownsville: The University of Texas Rio Grande Valley

\section{Gladis Fragoso}

UNAM Instituto de Investigaciones Biomedicas: Universidad Nacional Autonoma de Mexico Instituto de Investigaciones Biomedicas

\section{Juan P Laclette}

UNAM Instituto de Investigaciones Biomedicas: Universidad Nacional Autonoma de Mexico Instituto de Investigaciones Biomedicas

\section{Edda Sciutto ( $\nabla$ edda@unam.mx )}

Instituto de Investigaciones Biomédicas https://orcid.org/0000-0001-5608-5355

\section{Anai Fuentes Rodríguez}

Instituto de Investigaciones Biomédicas

\section{Research Article}

Keywords: Dexamethasone, intranasal administration, inflammation, neuroinflammation, COVID-19

Posted Date: September 28th, 2021

DOI: https://doi.org/10.21203/rs.3.rs-693766/v1

License: (c) (i) This work is licensed under a Creative Commons Attribution 4.0 International License. Read Full License 
INTRANASAL DEXAMETHASONE: A NEW CLINICAL TRIAL FOR THE CONTROL OF INFLAMMATION AND NEUROINFLAMMATION IN COVID-19 PATIENTS

${ }^{1}$ Graciela Cárdenas, ${ }^{2}$ Ana María Espinosa, ${ }^{3}$ María Chávez-Canales, ${ }^{3}$ Antonio Jordán-Ríos, ${ }^{2}$ Daniel Anica Malagon, , ${ }^{3}$ Manlio Fabio Márquez Murillo, ${ }^{3}$ Laura Victoria Torres Araujo, ${ }^{3}$ Ricardo Leopoldo Barajas Campos, ${ }^{4}$ Rosa María Wong, ${ }^{5}$ Luis Esteban Ramirez González, ${ }^{5}$ Karent Ibet Cresencio, ${ }^{5}$ Enrique García Velázquez, ${ }^{5}$ Mariana Rodriguez de la Cerda, ${ }^{3}$ Yoana Leyva, ${ }^{2}$ Joselin Hernández-Ruiz, ${ }^{2}$ María Luis Hernández-Medel, ${ }^{2}$ Mireya LeónHernández, ${ }^{6}$ Karen Medina Quero, ${ }^{6}$ Anahí Sánchez Monciváis, ${ }^{6}$ Sergio Hernández Díaz, ${ }^{6}$ Ignacia Rosalia Zeron Martínez, ${ }^{6}$ Adriana Martínez-Cuazitl, ${ }^{6}$ Iván Noé Martínez Salazar, ${ }^{6}$ Eduardo Beltrán Sarmiento, ${ }^{6}$ Aldo Figueroa Peña, ${ }^{6}$ Patricia Saraí Hernández Hernández, ${ }^{6}$ Rafel Ignacio Aguilar Reynoso, ${ }^{6}$ Daniela Murillo Reyes, ${ }^{6}$ Luis Rodrigo del Río Ambriz, ${ }^{6}$ Rogelio Antonio Alfaro Bonilla, ${ }^{1}$ Jocelyn Cruz, ${ }^{7}$ Leonor Huerta, ${ }^{7}$ Nora Alma Fierro, ${ }^{7}$ Marisela Hernández, ${ }^{8}$ Mayra Pérez-Tapia, ${ }^{9}$ Gabriela Meneses, ${ }^{10}$ Helgi Jung, ${ }^{7}$ Erick Espíndola-Arriaga, ${ }^{11}$ Gabriela Rosas, ${ }^{7}$ Roxana Olguin Alor, ${ }^{7}$ Sandra Ortega Francisco, ,${ }^{5}$ Alberto Chinney, ${ }^{12}$ Sergio Rosales Mendoza, ${ }^{7}$ Juan Alberto Hernández-Aceves ${ }^{7}$ Jaquelynne Cervantes-Torres, ${ }^{7}$ Anai Fuentes Rodríguez ${ }^{13}$ Hugo Besedovsky, ${ }^{14}$ Marta C. Romano, ${ }^{7}$ Raúl J. Bobes ${ }^{7}$ Gloria Soldevila, ${ }^{15} \mathrm{Juan}$ López Alvarenga ${ }^{7}$ Gladis Fragoso, ${ }^{7} \mathrm{Juan}$ Pedro Laclette, ${ }^{7}$ Edda Sciutto.

${ }^{1}$ Instituto Nacional de Neurología y Neurocirugía (INNN), Av. Insurgentes Sur 3877, La Fama, Tlalpan, 14269 Ciudad de México, México.

${ }^{2}$ Clinical Pharmacology Unit, Hospital General de México Dr. Eduardo Liceaga, Dr. Balmis 148, Doctores, Cuauhtémoc, 06720 Ciudad de México, México.

${ }^{3}$ Unidad de Investigación UNAM-INC, Instituto Nacional de Cardiología Ignacio Chávez and Instituto de Investigaciones Biomédicas, Universidad Nacional Autónoma de México, Juan Badiano No. 1, Col. Sección XVI, Tlalpan, 14080 Ciudad de México, México.

${ }^{4}$ Facultad de Medicina. Universidad Nacional Autónoma de México, 04510 Ciudad de México, México.

${ }^{5}$ Unidad Temporal COVID-19. Centro Citibanamex. Avenida del Conscripto 311, Lomas de Sotelo, 11200 Miguel Hidalgo, CDMX, México.

${ }^{6}$ Hospital Militar. Secretaría de la Defensa Nacional Periférico Blvrd Manuel Ávila Camacho s/n, Militar, Miguel Hidalgo, 11200 Ciudad de México, CDMX

${ }^{7}$ Departamento de Inmunología, Instituto de Investigaciones Biomédicas, Universidad 34 Nacional Autónoma de México, 04510 Ciudad de México, México.

${ }^{8}$ Unidad de Desarrollo e Investigación en Bioprocesos. Escuela Nacional de Ciencias Biológicas del Instituto Politécnico Nacional, Prolongación de Carpio y Plan de Ayala S/N, Col. Casco de Santo Tomas, Del. Miguel Hidalgo, 11340.Ciudad de México.

${ }^{9}$ Instituto de Diagnóstico y Referencia Epidemiológicos Dr. Manuel Martínez Báez. 
$40 \quad{ }^{10}$ Facultad de Química. Universidad Nacional Autónoma de México. 04510 Ciudad de 41 México, México.

$42 \quad{ }^{11}$ Facultad de Medicina. Universidad Autónoma del Estado de Morelos. Avenida Universidad 43 No. 1001, Chamilpa, 62209 Cuernavaca, Morelos. México.

$44 \quad{ }^{12}$ Universidad Autónoma de San Luis Potosí. Álvaro Obregón 64, Col. Centro, C.P. 78000

45 San Luis Potosí, S.L.P. México.

$46{ }^{13}$ Institute of Physiology and Pathophysiology, Emil-Mannkopff-Straße 2 u, 35037 Marburg,

47 Germany.

$48 \quad{ }^{14}$ Departamento de Fisiología, Biofísica y Neurociencias. Centro de Investigación y Estudios 49 Avanzados del Instituto Politécnico Nacional. Av. Instituto Politécnico Nacional 2508, San 50 Pedro Zacatenco, Gustavo A. Madero, 07360 Ciudad de México.

$51{ }^{15}$ University of Texas Rio Grande Valley - UTRGV. 1201 W University Dr, Edinburg, TX 5278539 , USA.

53 Send correspondence to: Edda Sciutto, $\mathrm{PhD}$, Department of Immunology, Instituto de 54 Investigaciones Biomédicas, Universidad Nacional Autónoma de México, Circuito escolar 55 s/n, 04510 Coyoacán, Mexico City, Mexico, (+52) 5622-3153; E-mail: edda@unam.mx

56 Word count: 3282 


\section{Graphical Abstract}

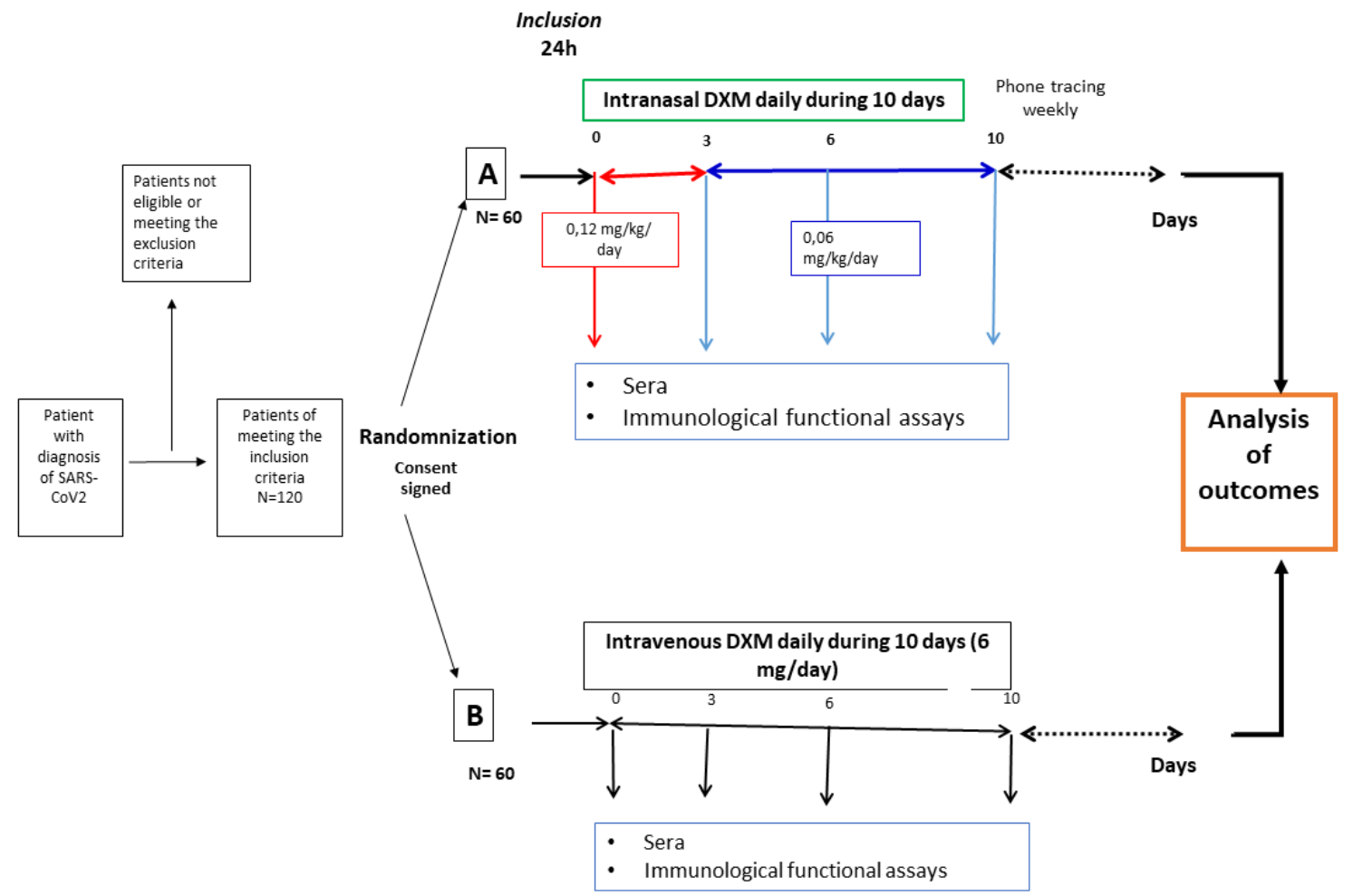

58

59

60

61

62

63

64

65

66

67

\section{Highlights}

- REVIVAL is a controlled, open-label multicentric study to compare the standard low doses of intravenous dexamethasone with low doses weight-adjusted of intranasal dexamethasone

- Intranasal dexamethasone can reach more effectively than intravenous the respiratory tract

- Intranasal dexamethasone can reach the central nervous system in therapeutic concentrations even at low doses

- REVIVAL aims to add to the control of systemic inflammation, the control of neuroinflammation to reduce central failures and sequelae 


\section{Abstract}

69 COVID-19 has produced more than 176 million infected individuals and almost 3.2 million 70 deaths worldwide. The infection results in a dysregulated systemic inflammation, multi-

71 organ dysfunction, and critical illness. Cells of the central nervous system (CNS) are also 72 affected triggering a dysregulated neuroinflammatory response.

73 Low doses of glucocorticoids (GCs) orally or intravenously administered has been proved to 74 reduce mortality of moderate and severe COVID-19 patients. However, low doses 75 administered by those routes do not reach therapeutic levels in the CNS. In contrast, if 76 dexamethasone is administered by the intranasal route can result in therapeutic doses in the 77 CNS even at low doses of the GC.

78 Methods: This is an approved multicentric randomized controlled protocol to compare the 79 effectiveness of low doses of intranasal dexamethasone versus intravenous administered in 80 adult moderate and severe COVID-19 patients. The protocol is conducted in five health 81 institutions in Mexico City. A total of 120 patients will be randomized in two groups

82 (intravenous vs intranasal) at 1:1 ratio, both groups will be treated with these dexamethasone 83 schemes for 10 days. The primary outcome of the study will be clinical improvement, defined 84 as a statistically significant higher reduction in the NEWS-2 score in intranasally versus 85 intravenously dexamethasone treated patients. The second outcome will be the reduction in 86 mortality during hospitalization.

87 Conclusions: This protocol is currently undertaken to improve the efficacy of the standard 88 therapeutic dexamethasone regimen for-moderate and severe COVID-19 patients. 
89 Trial registration: ClinicalTrials.gov identifier: NCT04513184 Registered November 12, 902020 and was approved by COFEPRIS with identifier DI/20/407/04/36. People are currently 91 being recruited.

92 Keywords: Dexamethasone, intranasal administration, inflammation, neuroinflammation, 93 COVID-19

94 


\section{Background}

96 So far, the outbreak of COVID-19 has caused more than 176 million infected individuals and

97 almost 3.2 million deaths worldwide (https://coronavirus.jhu.edu/map.html) with a current

98 global case-fatality ratio of $2.1 \%$, the most affected geographic region are the Americas with 99 a case-fatality ratio of $2.6 \%$.

100 Several factors predict a poor outcome for COVID-19 patients, such as comorbidities

101 (diabetes, hypertension, obesity) and aging with an underlying dysregulated inflammatory

102 response ${ }^{1}$. Other relevant factors include SARS-CoV-2 neurotropism/neuroinvasiness ${ }^{2-9}$. In

103 fact, the viral RNA was observed in the brain of patients that deceased by severe acute 104 respiratory syndrome due to COVID-19 infection ${ }^{10-12}$. Likewise, it was reported evidence 105 of astrocytic activation and neuronal damage in severe COVID-19 patients, which present 106 elevated plasmatic levels of GFAP and NfL ${ }^{13}$. Other authors have evaluated astrocytes ${ }^{14}$ 107 and neurons in 2D o 3D cultures showing an extensive infection ${ }^{15,16}$. The infection of cells 108 of the Central Nervous System results in the expression of PAMPs and DAMPs that trigger 109 a neuroinflammatory response. The exacerbated systemic inflammation with the 110 consequent breakdown of the blood-brain barrier and the migration of cells and peripheral 111 inflammatory mediators also contribute to increase to the in situ generated 112 neuroinflammatory response. Together, this dysregulated and sustained neuroinflammation 113 can add to peripheral damage, central (CNS) damage, which may contribute to the multi114 organ dysfunction and death ${ }^{10,12}$. 


\section{Natural history of SARS-CoV-2 infection}

118 A clinical staging system has been proposed in SARS-CoV-2 infection as follow, early

119 infection (Stage I, mild), pulmonary involvement (Stage IIa, moderate) without hypoxia, or 120 with hypoxia (Stage IIb), and finally Stage III (systemic hyperinflammation) ${ }^{17}$ (Figure 1).

121 After exposure to SARS-CoV-2, virus gains host access through the nasal cavity and 122 respiratory airway. During early infection (Stage I), mild and non - specific symptoms may 123 be observed (fever, malaise, and asthenia), upon this prodromic phase virus binds its target 124 ACE2, TMPRSS2 ${ }^{18,19}$ and more recently NRP-1 ${ }^{20,21}$. These receptors are highly present on 125 several tissues including the olfactory neuroepithelium (less in the sensitive olfactory 126 neurons) and lung ${ }^{19-22}$, consequently, the infection can be established in the lungs (Stage II) 127 and lead to viral pneumonia, cough, and fever with or without hypoxia. Here the SARS-CoV1282 PAMPs will be recognized by TLR3, TLR7 and TLR8 in the endosome but also in the RIG1291 like receptor in the cytosol ${ }^{23}$. The virus can also reach the CNS through the olfactory and 130 trigeminal nerves terminal. Once in the CNS it can infect and damage endothelial, pericytes 131 and neural cells that expressed ACE2, NRP-1 receptors ${ }^{20,21}$ promoting neuroinflammation 132 (Figure 1). CNS viral involvement is related to headache, dizziness, and ataxia, but infection 133 also may progress to the whole brain including the brainstem ${ }^{5,6}$. Finally, in a minority of 134 infected-patients disease progresses to Stage III where a hyperinflammatory syndrome (the 135 sustained production of proinflammatory cytokines including IL- $1 \beta$ and TNF $\alpha$ ) is observed, 136 with mitochondrial and lysosomal damage, expressing elevated proinflammatory cytokines, 137 reactive oxygen species (ROS), and the hyperactivation of $\mathrm{P} 2 \mathrm{X} 7$ receptors. These processes 138 induce inflammasome activation (which increased IL-6 levels) and lead to pyroptosis which 
139 determines a persistent inflammatory cycle by disseminating viral antigens and RNA in the 140 circulation. Thereafter, it is possible the generation of immune complex and its deposition in 141 target organs ${ }^{23-25}$. During this phase, sustained neuroinflammation may exacerbate the 142 neuronal injury, therefore spreading damage and contributing towards central respiratory 143 failure besides other signs of systemic organ involvement resulting in multi-organ 144 dysfunction ${ }^{17}$.

145 A crucial strategy to treat COVID-19 patients seems to be the control of neuroinflammation 146 and systemic inflammation. For this purpose, it is important to consider how the virus invades 147 the human organism. The most frequent form is the intranasal route which allows a direct 148 access to both, the respiratory and the central nervous systems through neural pathways $5 ; 15$ 149 18. Coronaviruses including SARS-CoV-2 can infect brainstem neurons associated with 150 cardio-respiratory control, which induces central alterations of pulmonary function ${ }^{5 ; 26-29}$. In 151 fact, COVID-19 neurological clinical symptoms particularly nausea, vomiting, and dysgeusia 152 appear to involve the dorsal vagal complex (DVC) and the nucleus tractus solitary (NTS) 153 linked to the control of several autonomic functions ${ }^{26}$. The NTS is a well-known target of 154 neuro-immune activation ${ }^{33}$, and its ascending projections reach the hypothalamus 155 (hypothalamic paraventricular nucleus) involved in the HPA axis activation while other NTS 156 projections come to the rostral ventrolateral medulla (RVM), which controls respiratory and 157 cardiovascular functions ${ }^{34}$.

158 The viral infection in respiratory and central nervous system cells promotes the expression 159 of pathogen-associated molecular patterns (PAMPs) and damage-associated molecular 160 patterns (DAMPs) signals that in turn trigger inflammasome and oxidative stress ${ }^{23,35}$. Later 
161 during infection, inflammatory response may become dysregulated extending the initial 162 damage caused by the infection.

\section{Adrenal affection in SARS-CoV-2 infection}

164 Critically ill-patients of different pathologies frequently show adrenal insufficiency which 165 may increase morbidity and mortality ${ }^{36,37}$. COVID-19 might affect the hypothalamic166 pituitary-adrenal (HPA) axis as well. Hypothalamic and hypophysis tissues do express ACE2 167 and can therefore be viral targets ${ }^{38}$. The virus may directly damage the hypothalamus as well 168 as the pituitary leading to hypothalamo-pituitary dysfunctions. In fact, since SARS outbreak 169 in 2003, it was observed that coronavirus affects the HPA axis, and vasculitis was 170 demonstrated by autopsy studies in several organs including adrenal glands, particularly 171 adrenal cortical cells undergo degeneration and necrosis ${ }^{39}$. Although the full spectrum of 172 COVID-19 endocrinological manifestations within long-term is still unclear, several 173 endocrine alterations have been reported in SARS survivors, as well as hypocortisolism, and 174 hypothyroidism, and low levels of dehydroepiandrosterone, which suggested a transient 175 hypothalamic-pituitary dysfunction ${ }^{40}$. Recently, an Arabian study in 28-patients reported the 176 adrenal response to an acute COVID-19 infection, the median morning cortisol level was 196 177 (31-587) nmol/L, the ACTH median level of 18.5 (4-38ng/L). Interestingly, severe forms 178 patients had lower cortisol and $\mathrm{ACTH}{ }^{41}$. In addition, in other autopsy studies, edema, 179 neuronal degeneration and evidence of viral genome were found in the hypothalamus ${ }^{42}$ Thus, 180 in the presence of subacute thyroiditis or adrenal insufficiency, corticosteroid therapy should 181 help in reduced high amounts of thyroid hormones, and replace adrenal function, improving 182 the evolution of these patients, regardless the route of administration. 


\section{Rationale}

184 Dexamethasone sodium phosphate (ALIN, injectable solution. Chinoin Laboratory) is a 185 highly soluble glucocorticoid with a neutral $\mathrm{pH} 7-8.5$, which did not injury the nasal mucosa. 186 This synthetic steroid is an anti-inflammatory and immunomodulator drug that inhibits 187 prostaglandins and leukotrienes synthesis, platelet activation, and coagulation through 188 regulation of transcriptional factors such as NFK- $\beta$ y AP-1 ${ }^{43,44}$. In addition, it can sensitize 189 the cells to extracellular ATP during NLRP3 induction, which enhances the release of 190 proinflammatory molecules ${ }^{45}$. In addition, it has been reported that DXM exerts important 191 neuroprotective effects as rescue the neurovascular integrity during neuroinflammation ${ }^{46}$. 


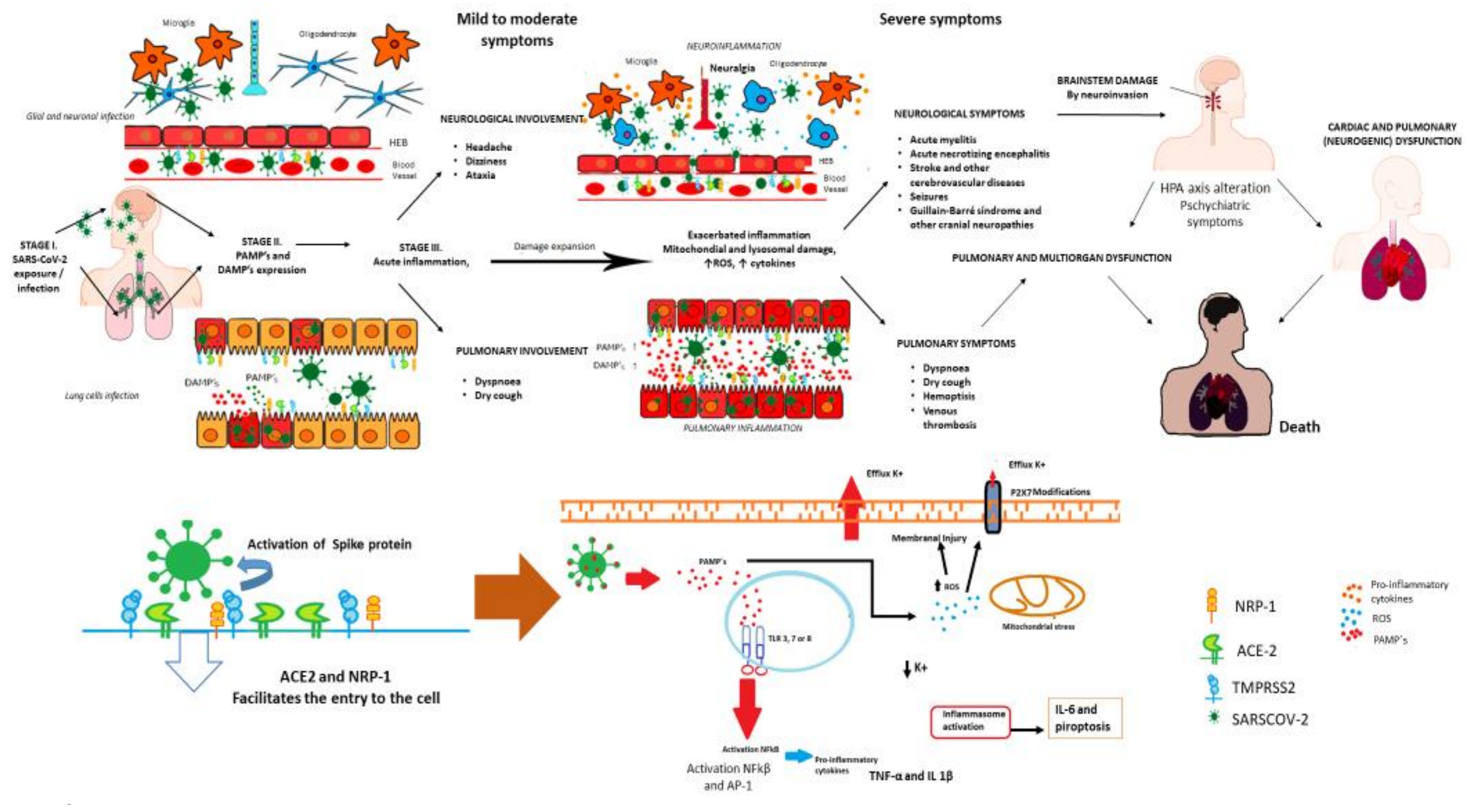

193 Figure 1. 


\section{Dexamethasone a potent anti-inflammatory drug}

195 Considering that complications of COVID-19 result from exacerbated and uncontrolled 196 peripheral inflammation and neuroinflammation, derived from the so-called cytokine storms, 197 at least three important and key points have been considered in the use of DXM for the 198 treatment of victims of the Coronavirus: the timing, the dose, and the route of administration 199 of the steroid. First, the drug would not be applied from the beginning of the infection, the 200 time at which the inflammation favors the host. It should be given to promote the installation 201 of an adaptive immune response and thus control the infection. A low dose of DXM (6 mg 202 per patient for 10 days) applied to quickly and effectively control pulmonary inflammation 203 with minimal negative side effects ${ }^{47}$. In addition, the intranasal route would allow direct 204 access of the DXM to the CNS, thereby controlling the sustained neuroinflammation 205 provoked by damage to infected astrocytes, neurons and microglia during the progression of 206 COVID that cause the fatal central respiratory and cardiac failure in these patients.

207 It is well known that drugs administered intranasal usually permit higher bioavailability in 208 CNS without the need of BBB pass or hepatic degradation, in comparison with similar 209 intravenous doses administered in experimental models 55, 56-58. In addition, the 210 administration of DXM by this route induces an inflammatory control by arriving directly to 211 the respiratory system, more effectively and quickly than by using intravenous route ${ }^{56-59}$. 212 DXM prevents the binding of ACE2 to spike protein of SARS-CoV-2 and can bind LYS353, 213 an active residue of $\mathrm{RBD}^{60}$, and reduces ACE2 expression in several types of cells by 214 suppressing type I interferon expression ${ }^{61}$, can also downregulate neutrophils extracellular 215 traps, possibly through Toll-like receptor regulation ${ }^{62}$. It is known that hyper inflammation 
216 is related to high levels of NETs which is related to ARDS in which neutrophilia predicts

217 thrombosis and poorer outcomes ${ }^{63,64}$.

\section{METHODS}

\section{Trial design}

220 The "REVIVAL trial" an interventional study, phase 2, multicentric randomized controlled 221 in adult patients with confirmed COVID-19 diagnosis was designed to evaluate the efficacy 222 of low doses of intranasal DXM compared to intravenous administration in patients of five 223 COVID-19 referral centers in Mexico City. This protocol is supported in part by the 224 Institutional grant "Programa de Investigación para el Desarrollo y la Optimización de 225 Vacunas, Inmunomoduladores y Métodos Diagnósticos del Instituto de Investigaciones 226 Biomédicas", UNAM (DGAPA-UNAM, PAPIIT IN201020), as well as by another specific 227 grant provided by the Mexican Ministry of Foreing Affairs (Secretaria de Relaciones 228 Exteriores) and Mexican Agency for International Development Cooperation (AMEXCID) 229 with identifier: 318.01 fund MEX-CHI. This trial is being coordinated at the Department of 230 Immunology of the Biomedical Research Institute, UNAM.

\section{Settings}

232 This clinical trial is being conducted at the following Institutions "Hospital General de 233 México Dr. Eduardo Liceaga”, “Instituto Nacional de Neurología y Neurocirugía Manuel 234 Velasco Suárez", "Instituto Nacional de Cardiología Ignacio Chavez”, "COVID-19 unit at 235 Citibanamex" and "Hospital Central Militar" all of them in Mexico City. 


\section{Eligibility criteria}

238 Inclusion criteria includes patients of both sexes, (non-pregnant female) 18 years of age and 239 under 90 years, with presumptive SARS-CoV-2 infection with more than 5 days of clinical 240 evolution and with moderate to severe symptoms requiring oxygen support or high flux 241 mechanical ventilation (NEWS-2 $\geq 5$ ), abnormal CT- chest scan CO-RADS $>3$. Patients 242 diagnosed with atypical pneumonia, confirmed by chest images and oxygen saturation $243\left(\mathrm{SpO}_{2}\right)$ less than $93 \%$ in ambient air or when a ratio of the partial pressure of oxygen $\left(\mathrm{PaO}_{2}\right)$ 244 and the fraction of inspired oxygen $\left(\mathrm{FiO}_{2}\right)\left(\mathrm{PaO}_{2}: \mathrm{FiO}_{2}\right)$ was $300 \mathrm{~mm} \mathrm{Hg}$ or less, and a 245 confirmatory RT- PCR SARS-CoV-2 positive test. These patients will be allocated into the 246 experimental group or the control group in a ratio 1:1 (two arms) (Fig. 2) according to the 247 randomization.

248 Exclusion criteria includes patients with RT-PCR SARS-CoV-2 negative test, those 249 receiving previously GCs at high doses, by oral or intravenous administration, or severely 250 immunosuppressed as in AIDS, pregnancy; autoimmune disease patients as well as those 251 who have received outpatient treatment with steroids for more than 72 hours prior to hospital 252 admission, older than 90 years, or with DXM allergy, risk for glaucoma or recurrent 253 respiratory diseases.

254 Elimination criteria will be considered in case of voluntary withdrawing or lacking informed 255 consent, or imminent risk of death within $48 \mathrm{hrs}$.

256 The pharmacovigilance staff of each hospital will perform a continuous monitoring each 72 257 hours during the period of study (including all adverse events). 


\section{Groups and comparators}

261 The study will be carried out in two groups, group A (experimental) that will receive 262 intranasal DXM, and group B (Control) that will receive intravenous DXM (Fig.2), based on 263 the previously reported data, where the intranasal administration can reach the brain and

264 bloodstream more quickly and efficiently ${ }^{56-59}$. Group A will receive daily intranasally DXM 265 at a dose of- $0.12 \mathrm{mg} / \mathrm{kg}$ for the first three days, that will be followed by seven days at a dose 266 of $0.06 \mathrm{mg} / \mathrm{kg}$. Group B will receive daily $6 \mathrm{mg}$ intravenous DXM. In both groups, a close 267 follow-up will be done by the pharmacovigilance staff every 72 hours, they will assess 268 whether it is appropriate for the patients to continue within the protocol.

\section{Procedures}

270 A double follow-up form (written and online) will be filled for each patient, and completed 271 at the end of treatment or fatal outcome after randomization, whatever occurs first. Besides 272 a daily clinical evaluation, blood and saliva samples will be collected every third day during 273 the whole treatment period, to perform ancillary tests as SARS-CoV-2 viral load, functional 274 immunological assessment (lymphocyte cytometry, cytokines / chemokines profile), as well 275 as cortisol levels, among other analysis. All human samples will be stored at $-70^{\circ} \mathrm{C}$ until use. 276 All patient's personal data and medical information will be treated in a strictly confidential 277 way. Only the lead investigator and the hospital coordinator investigators will have access. 


\section{Participants}

281 The sample includes 120 adult patients between 18 and 90 year-olds, both sexes with 282 moderate and severe forms of COVID-19.

\section{Sample size and Randomization}

284 The sample size was calculated with EPIDAT version 3.1.2 software, with the option 285 "Sample size and surveillance curves" with an estimation of 50\% increase in the proportion 286 of patients free of mechanical ventilation [intranasal DXM 70\% vs intravenous DXM 45\%].

287 This value was estimated based on the data of the COVID-19 patients registered in Mexican 288 hospitals with a confidence of $95 \%$, power of $80 \%$ and proportion of losses of $10 \%$, with 289 these characteristics is obtained 60 per group. The randomization will be making with Sealed 290 Envelope software. This software is a freeware [Online] available from: 291 https://www.sealedenvelope.com/simple-randomiser/v1/lists [Accessed 5 May 2020]. This 292 study is a multicenter randomized controlled trial. (Fig. 2)

\section{Confidentially}

294 Each patient who agrees to participate in the protocol will be assigned an identification 295 number, which will be used to check out throughout the procedure. This code identifies the 296 hospital of origin and the patient identification number. All the information collected during 297 the procedure will be confidential and used for the research purpose only and follow up for 298 any adverse effect. 


\section{Outcomes}

302 The expected primary outcome is clinical improvement, defined as a two-point improvement 303 of ordinal scale regarding the initial NEWS-2 score. The secondary expected outcome 304 includes a reduction in mortality that will be follow-up during treatment (after 305 randomization), as well as a reduction of the time required for mechanical ventilation and the 306 length time of patient's stay in hospital. Viral load, several other physiological parameters 307 and the immune-inflammatory profile will also be evaluated before and after treatment (see 308 above).

309 Data collection and management

310 The patient receives an informed consent letter, where the characteristics of the procedure 311 are detailed, if he accepts, the letter will be signed and the patient will be randomized; saliva 312 and nasopharyngeal sample will be taken to know the viral load and treatment will begin as 313 indicated in figure 2; a clinical history will be made based on the initial results and physical 314 inspection of the patient.

315 The samples taken will be sent for specialized analysis following standardized operating 316 procedures (SOP's) for the analysis.

\section{Plans to promote participant retention and complete follow-up}

318 All participants in the research protocol will receive specialized medical care, by monitoring 319 continuously clinical, neurological, and neuropsychological studies. These evaluations will 320 be carried out to monitor the evolution of the disease at 1, 3, 6, and 12 months after COVID-

321 19. Those participants presenting some functional decline post COVID will be received 
322 medical treatment and neurorehabilitation.

323 Likewise, for patients who present an adverse effect or health problem during its participation

324 in the dexamethasone treatment study or derivate to it upon hospitalization, the General

325 Hospital of Mexico Dr. Eduardo Liceaga will take care of the necessary treatment and/or care

326 until their resolution. In addition, patients will be monitored every 3 months for 1 year after

327 the study

328 Management

329 The information collected during the procedure will be documented physically and digitally

330 in an exact and precise way. Each complete patient report will be used by researchers in

331 conjunction with the molecular and immunological tests to analyze the outcomes. The

332 information collected will be treated as confidential, and only the global results will be

333 published without showing the names of the patients, in case the data is required, the

334 information can be request to the researchers with valid reasons.

\section{Analysis of outcomes}

336 A database will be built, and a descriptive statistic will be performed. The data distribution

337 will be analyzed and compared with DXM route of administration with a multivariable 338 analysis: nested ANOVA with repeated measures and Markov test. The analysis will be done 339 with a R software (4.0.0, Arbor Day). A statistical difference with $P<0.05$ will be considered 340 significant. 


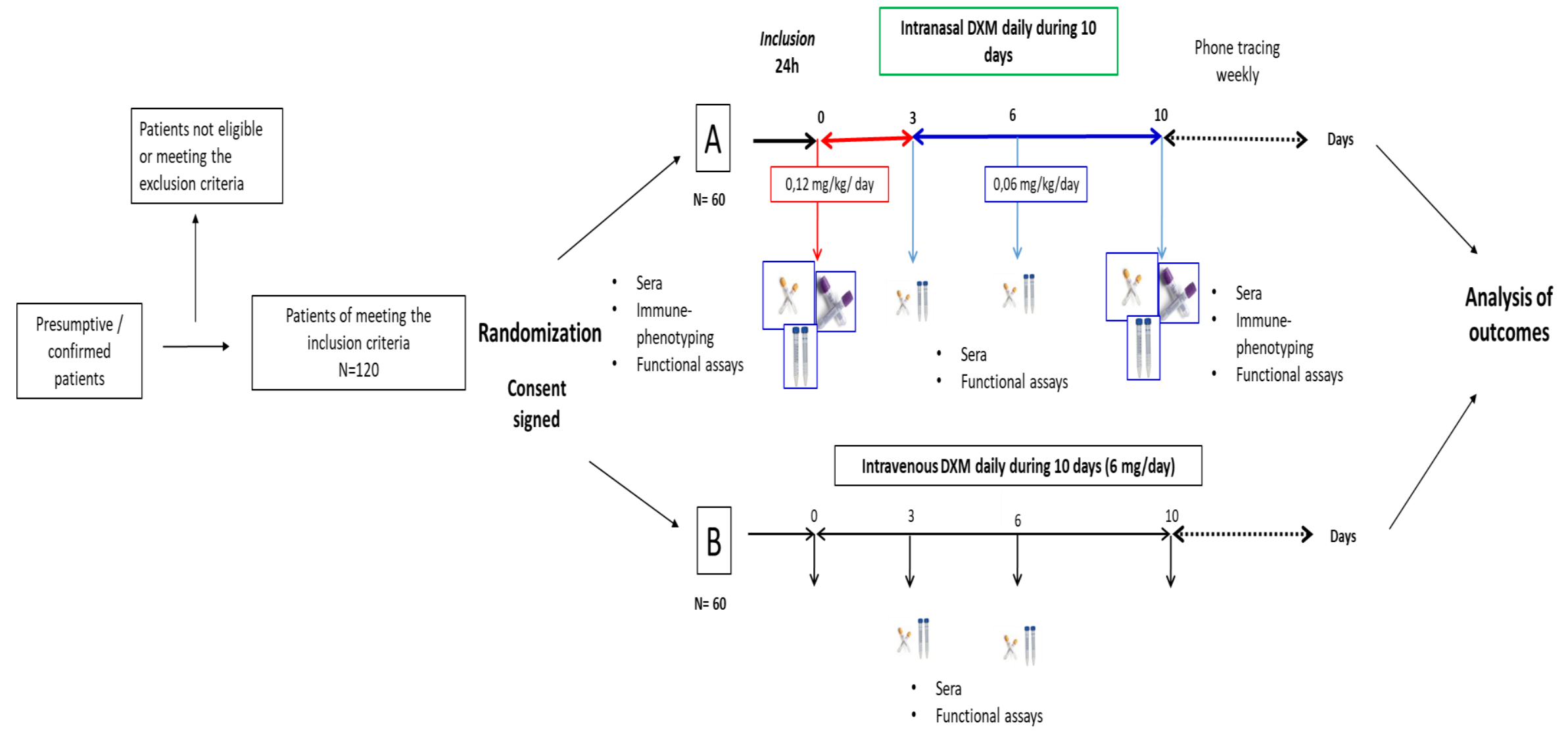

342 Figure 2. 
345 Intranasal DXM at low doses could be a more effective therapeutic option to control 346 inflammation and neuroinflammation during ARDS in severe and critical forms of SARS347 CoV-2 infection. In addition, it could aid the HPA axis upon this severe stress condition. 348 DXM in low doses applied by systemic route although beneficial for COVID-19 patients, 349 cannot reach effective therapeutic concentration in the CNS to control neuroinflammation. 350 In contrast, intranasal administration of DXM is highly effective to control 351 neuroinflammation as demonstrated in experimental models of several inflammatory 352 conditions ${ }^{44-47}$. Therefore, in the REVIVAL trial clinical protocol, we propose boosting the 353 effect of DXM treatment at low doses in COVID-19 through an intranasal route of 354 administration to reach CNS at therapeutic doses that may effectively reduce the morbidity 355 and mortality in severe or critical COVID-19 patients, even more than that reported data in 356 the RECOVERY trial.

357 A randomized study in hospitalized COVID-19 patients (moderate and severe forms), the 358 intranasal DXM at low doses (clinicaltrials.gov id: NCT04513184) is being tested. The 359 clinical evolution and respiratory parameters of the patients receiving intranasal DXM 360 (experimental treatment) is compared with recommended treatment of $6 \mathrm{mg}$ of intravenously 361 DXM (https://www.covid19treatmentguidelines.nih.gov/). Considering the prevalence of 362 metabolic syndrome and obesity in Mexico, a therapeutic scheme weight-adjusted at low 363 dose is being applied i.e., three-day schedule of $0.12 \mathrm{mg} / \mathrm{kg}$ and 7 days at $0.06 \mathrm{mg} / \mathrm{kg}$. If the 364 current approach results less prone to adverse effects but enough to reach CNS and control 365 neuroinflammation as we hypothesized, there will be direct interest to extent this protocol to 
366

367

368

369

370

371 The study was registered under the platform Clinical Trials from NCBI in August 2020, and 372

373 being recruited.

$374 \quad 6.2$ Ethics declarations

375 This study was reviewed and approved by the Committees of Ethics, Research and 376 Biosecurity of the five Hospitals committees. Hospital General de México "Dr. Eduardo 377 Liceaga" (DI/20/407/04/36), Instituto Nacional de Neurología y Neurocirugía (INNN 31/20) 378 and Instituto Nacional de Cardiología (INCICh: 20-1167), temporary unit for COVID 379 Citibanamex, and Hospital Central Militar (FM/DI/107/SR/2020), and is approved for 380 COFEPRIS with identifier DI/20/407/04/36.

381 All participants will provide a written informed consent before enrollment and all the work 382 will be conducted according to the Helsinki statements.

\subsection{Availability of data and materials}

Data and materials are not available at this moment, because the work being considered is 385

the first approach to a clinical trial currently started. When the study will be completed, the 
386 dataset obtained and analyzed will be available from the corresponding author only by 387 reasonable request.

$388 \quad 6.4$ Funding

389 This work were supported by Dirección General de Personal Académico, UNAM

390 (DGAPA-UNAM, PAPIIT IV201020), by the Institutional program "Programa de

391 Investigación para el Desarrollo y la Optimización de Vacunas, Inmunomoduladores y

392 Métodos Diagnósticos del Instituto de Investigaciones Biomédicas" U.N.A.M as well by

393 the Mexican Ministry of Foreing Affairs (Secretaria de Relaciones Exteriores) and Mexican

394 Agency for International Development Cooperation (AMEXCID) with identifier: 318.01

395 fund MEX-CHI.

$396 \quad 6.5$ Conflict of interest

397 The authors have no other relevant affiliations or financial involvement with any organization

398 or entity with a financial interest in or financial conflict with the subject matter or materials

399 discussed in the manuscript apart from those disclosed.

\section{Author's contributions}

401 Study concept and design: GC, ES, HB, MR, JH, MCC

402 Data adquisition and interpretation: GC, ES, HB, MR, JH, MCC, AJR, DAM, MFMM, LVTA, 403 RLBC, RMW, LERG, KIC, EGV, MRC, YL, MLHM, MLH, KMQ, ASM, SHD, IGRZM, AMC, 404 INMS, EBS, AFP, MJFM, PSHH, JC, LH, NAF, MH, MPT, GM, HJ, EEA, GR, ROA, SOF, SRM, 405 JAHA, JCT, AFR, HB, MCR, RJB, GS, JLA, GF, JPL.RIAR, DMR, LRRA, RAAB

406 Manuscript drafting: GC, ES, HB, MR, JH, JAHA, MCR, RJB, GS, JLA, GF, JPL 
407 Critical revision of the manuscript for important intellectual content: GC, ES, HB, MR, JH, JAHA,

408 MCR, RJB, GS, JLA, GF, JPL

$409 \quad$ 8. Consent for publication

$410 \quad$ Not applicable

4119 9. Acknowledgements

$412 \quad$ Not applicable

$413 \quad 10$. List of abbreviations

414 DVC: Dorsal Vagal Complex

415 NTS: Nucleus Tractus Solitary

416 HPA: Hypothalamic Pituitary Adrenal axis

417 RVM: Rostral Ventrolateral Medulla

418 DAMP: Damage-Associated Molecular Patterns

419 PAMP: Pathogen-Associated Molecular Patterns

420 DXM: Dexamethasone

421 GCs: Glucocorticoids

422 ACE2: Angiotensin-Converting Enzyme 2

423 TMPRSS2: Transmembrane Protease Serine 2

424 CNS: Central Nervous System

425 ROS: Reactive Oxygen Species 
426 NFK-B: Nuclear Factor K beta

427 AP-1: Activator Protein 1

428 ARDS: Severe Acute Respiratory Distress Syndrome

429 BBB: Blood Brain Barrier

430 NET: Neutrophil Extracellular Traps

431 


\section{Figure Legends}

433 Figure 1. Inflammatory phenomenon associated with SARS-CoV-2 infection and its 434 neurological and respiratory manifestations. The SARS-CoV-2 virus enters mainly by air and reaches the lungs through direct ventilation and the CNS through the olfactory and trigeminal

436 nerve, the entry of the virus is facilitated by NRP-1, ACE2 receptors and the protein S 437 activation by TMPRSS2. In the CNS, the virus infects neurons, glial cells, and endothelial 438 cells, increasing the permeability of the BBB, and may cause cerebral edema and intracranial 439 hypertension, as well as neuroinflammation. If the viral infection continues, the damage 440 spreads throughout the body causing heart and systemic failure. This damage is associated 441 with an increase in neuroinflammation, directed by microglia and oligodendrocytes, causing 442 damage to the brain stem, and causing a dysfunctional state of the heart and lung. Likewise, 443 in the lung, due to exacerbated inflammation and intravascular coagulation, respiratory arrest 444 is induced that can lead to the patient death. The inflammation is conducted by the cellular 445 activation trough TLR3, 7 and 8 for components from the virus (PAMPS) and subsequent 446 production of pro-inflammatory cytokines (TNF $\alpha$ and IL 1 $1 \beta$ ) and generation of ROS; those 447 ROS can be able to modify the P2X7 receptor in the brain and activate the inflammasome by 448 the decrease of $\mathrm{K}^{+}$. The activation of inflammasome increases the production of IL- 6 and 449 pyroptosis.

450 Figure 2. Outline of the REVIVAL trial clinical protocol. Initially, patients will be informed 451 about the clinical trial, if they accept and sign the consent, they will be randomized using the 452 Sealed envelope ${ }^{\circledR}$ software. Group A receive DXM intranasally obtaining serum and a swab 453 on days $0,3,6$ and 10 post treatment. On the other hand, group B receive intravenous DXM, 454 obtaining the same samples on the same days $0,3,6$ and 10. Throughout the study, the patients 
455 are monitored. Once the results are obtained, these are analyzed to define if exist a 456 statistically difference between groups. 


\section{References}

458 [1] Medzhitov R. Origin and physiological role of inflammation. Nature (2008) 454:428$459 \quad 35.10 .1038 /$ nature07201.

460 [2] Li YC, Bai WZ, Hashikawa T. The neuroinvasive potential of SARS-CoV2 may play a 461 role in the respiratory failure of COVID-19 patients. J Med Virol. 2020;92:552-555

462 [3] Zhou Z, Kang H, Li S, Zhao X. Understanding the neurotropic characteristics of SARS463 CoV-2: from neurological manifestations of COVID-19 to potential neurotropic 464 mechanisms. J Neurol. 2020;267(8):2179-2184

465 [4] Ng Kee Kwong, Koy Chong, Puja R. Mehta, Garima Shukla, and Arpan R. Mehta. 2020. 466 "COVID-19, SARS and MERS: A Neurological Perspective." Journal of Clinical 467 Neuroscience. Churchill Livingstone. https://doi.org/10.1016/j.jocn.2020.04.124.

468 [5] Li YC, Bai WZ, Hirano N, Hayashida T, Hashikawa T. Coronavirus infection of rat dorsal 469 root ganglia: ultrastructural characterization of viral replication, transfer, and the early 470 response of satellite cells. Virus Res. 2012;163(2):628-635

471 [6] Desforges M, Le coupanec A, Dubeau P, Bourgouin A, Lajoie L, Dubé M, Talbot PJ. 472 Human coronaviruses and other respiratory viruses: underestimated opportunistic pathogens 473 of the central nervous system? Viruses 2019;12(1):14

474 [7] Gasmi A, Noor S, Menzel A, Dosa A, Pivina L, Bjoorklund G. Obesity and Insulin 475 Resistance: Associations with Chronic Inflammation, Genetic and Epigenetic Factors. Curr 476 Med Chem 2020. doi: 10.2174/0929867327666200824112056. 
477 [8] Liu Danlin, Richardson G, Benli FM,Park C, de Souza JV, Bronowska AK, 478 Spyridopoulos. Inflammageing in the cardiovascular system: mechanisms, emerging targets, 479 and novel therapeutic strategies. Clin Sci (Lond) 2020; 134(17):2243-2262.

480 [9]Meinhardt J, Radke J, Dittmayer C et al. Olfactory transmucosal SARS-CoV-2 invasion 481 as a port of a central nervous system entry in individuals with COVID-19. Nat Neurosci $482 \quad 2021 ; 24(2): 1698-175$

483 [10] Dos Santos MF, Devalle S, Aran V, Capra D, Roque NR, Coelho-Aguiar JM, Spohr 484 TCLSE, Subilaga JG, Pereira CM, D’Andrea Meira I, Niemeyer Soares Filho P, Moura-Neto 485 V. Neuromechanisms of SARS-CoV-2: A review. Front Neuroanat. 2020;14:37

486 [11] Somolon IH, Normandin E, Bhattacharyya S, Mukerji SS, Kellner K, Ali AS, Adams G, 487 Hornick JL, Padera RF Jr, Sabeti P. Neuropathological features of COVID-19. N Engl J Med $488 \quad 2020 ; 383 ; 989-992$

489 [12] Paniz-Mondolfi A, Bryce C, Grimes Z, Gordon RE, Reidy J, Lednicky J, Sordillo EM, 490 Fowkes M. Central nervous system involvement by severe acute respiratory syndrome 491 coronavirus-2 (SARS-CoV-2). J Med Virol. 2020;92(7):699-702

492 [13] Kanberg N, Ashton NJ, Andersson LM, Yilmaz A, Lindh M, Nilsson S, Price RW, 493 Blennow K, Zetterberg H, Gisslén M. Neurochemical evidence of astrocytic and neuronal 494 injury commonly found in COVID-19. Neurology. 2020;e1754-e1759.

495 [14] Andrews MG, Mukhtar T, Enze UC, Simoneau CR, Perez Y, Mostajo-Radji MA, Wang 496 S, Velmeshev D, Salma J, Kumar GR, Pollen AA, Crouch EE, Ott M, Kriegstein AR.Tropism 
497 of SARS-CoV-2 for developing human cortical astrocytes. Version 1. bioRxiv. Preprint.2021

$498 \quad$ Jan 18. Doi:10.1101/2021.01.17.427024

499 [15] Ramani A, Müller L, Ostermann PN, Gabriel E, Abida-Islam P, Müller-Schiffmann A, 500 Mariappan A, Goureau O, Gruell H, Walker A, Andrée M, Hauka S, Houwaart T, Dilther A, 501 Wohlgemuth K, Omran H, Klein F, Wieczorek D, Adams O, Timm J, Korth C, Schaal H, 502 Gopalakrishnan J. SARS-CoV-2 targets neurons of 3D human brain organoids. EMBO J. $503 \quad 2020 ; 39: \mathrm{e} 106230$

504 [16] Song E, Zhang Ce, Israelow B, Lu-Culligan A, Veites Prado A, Skriabine S, Lu P, Orr505 El Weizman L, Lui F, Dai Y, Szigeti-Buck K, Yasumoto Y, Wang G, Castaldi C, Heltke J, 506 Ng E, Wheeler J, Madel Alfajaro M, Levavasseur E, Fontes B, Ravindra NG, van Dijk D, 507 Gunel M, Ring A, Jaffar Kazmi SA, Khang K, Willen CB, Horvath TL, Plu I, Haik S, Thomas 508 JL, Louvi A, Farhadian SF, Huttner A, Seilhean D, Renier N, Bilguvar K, Iwaski A. 509 Neuroinvasion of SARS-CoV-2 in human and mouse brain. J Exp Med. 2021;218:e20202135

510 [17] Siddiqi HS, Mehra MR. COVID-19 illness in native and immunosuppressed states: A 511 clinical-therapeutic staging proposal. J Heart Lung Transplant. 2020;39(5):405-407

512 [18] Hoffmann, Markus, Hannah Kleine-Weber, Simon Schroeder, Nadine Krüger, Tanja 513 Herrler, Sandra Erichsen, Tobias S. Schiergens, et al. 2020. "SARS-CoV-2 Cell Entry 514 Depends on ACE2 and TMPRSS2 and Is Blocked by a Clinically Proven Protease Inhibitor." 515 Cell 181 (2): 271-280.e8 https://doi.org/10.1016/j.cell.2020.02.052

516 [19] Sungnak W, Huang N, Becavin C, et al. SARS-CoV-2 entry factors are highly expressed 517 in nasal epithelial cells together with innate immune genes. Nat Med 2020; 26: 681-687. 518 doi:10.1038/s41591-020-0868-6 
519 [20] Cantuti-Castelvetri L, Ojha R, Pedro LD, Djannatian M, Franz J, Kuivanen S, van der 520 Meer F, Kallio K, Kaya T, Anastasina M, Smura T, Levanov L, Szirovicza L, Tobi A, Kallio521 Kokko H, Österlund P, Joensuu M, Meunier FA, Butcher SJ, Winkler MS, Mollenhauer B, 522 Helenius A, Gokce O, Teesalu T, Hepojoko J, Vapalahti O, Stadelmann C, Balistreri G, 523 Simons M. Neuropilin-1 facilitates SARS-CoV-2 cell entry and infectivity. Science $524 \quad 2020 ; 370: 856-860$.

525 [21] Davies J, Randeva HS, Chatha K, Hall M, Spandidos DA, Karteris E, Kyrou I. 526 Neuropilin-1 as a new potential SARS-CoV-2 infection mediator implicated in the 527 neurologic features and central nervous system involvement of COVID-19. Mol Med Rep. $528 \quad 2020 ; 22: 4221-4226$

529 [22] Butowt, R. and Bilinska, K. (2020) SARS-CoV-2: Olfaction, brain infection and the 530 urgent need for clinical samples allowing earlier virus detection. ACS Chem. Neurosci. 11 531 (9), 1200- 1203, doi: 10.1021/acschemneuro.0c00172

532 [23] Yap JKY; Moriyama M, Iwasaki A. Inflammasomes and pyroptosis as therapeutic 533 targets for COVID-19. J Immunol. 2020;205(2):307-312

534 [24] Freeman TL, Swartz TH. Targeting the NLRP3 inflammasome in severe COVID-19. 535 Front Immunol. 2020;11:1518

536 [25] Ribeiro Dem Oliveira-Giacomelli A, Glaser T, Arnaud.Sampaio VF, Andrejew R, 537 Diekmann L, Baranova J, Lameu C, Ratajczak M, Ulrich H. Hyperactivation of P2X7 538 receptors as a culprit of COVID-19 neuropathology. Mol Psychiatry 2020;1-16 
539 [26] Netland J, Meyerholz DK, Moore S, Cassell M, Perlman S. Severe acute respiratory 540 syndrome coronavirus infection causes neuronal death in the absence of encephalitis in mice 541 transgenic for human ACE2. J Virol. 2008;82(15):7264-7275.

542 [27] Wu Y., Xu X., Chen Z., Duan J., Hashimoto K., Yang L. Nervous system involvement 543 after infection with COVID-19 and other coronaviruses. Brain Behav. 544 Immun. 2020;20 30357-3.

545 [28] Zhou L., Zhang M., Wang J., Gao J. Sars-Cov-2: underestimated damage to nervous 546 system. Travel Med. Infect. Dis. 2020 doi: 10.1016/j.tmaid.2020.101642.

547 [29] Sun T., Guan J. Novel coronavirus and central nervous system. Eur. J. Neurol. 2020 doi: $548 \quad 10.1111 /$ ene.14227.

549 [30] Gandhi S, Srivastava AK, Ray U, Tripathi PP. Is the collapse of the respiratory center 550 in the brain responsible for respiratory breakdown in COVID-19 patients? ACS Chem 551 Neurosci 2020. https://doi.org/10.1021/acschemneuro.0c00217

552 [31] Misra R, Florez-Perdomo WA, Vasquez HE, Moscote-Salazar LR, Agrawal A. SARS$553 \mathrm{CoV} 2$ and the pathobiology of the respiratory control mechanism in the brainstem. J Formos 554 Med Assoc. 2020: S0929-6646(20)30347-8

555 [32] Chigr F, Merzouki M, Najimi M. Autonomic brain centers and pathophysiology of 556 COVID-19. ACS Chem Neurosci 2020;11(11):1520-1522

557 [33] Cai Y, Hay M, Bishop VS. Synaptic connections and interactions between area postrema 558 and nucleus tractus solitarius. Brain Res.1996; 724, 121-124. doi: 10.1016/0006559 8993(96)00282-X 
560 [34] Goodchild AK, Moon EA. Maps of cardiovascular and respiratory regions of rat ventral

561 medulla: focus on the caudal medulla. J Chem Neuroanat. 2009;38(3):209-21

562 [35] Delgado-Roche L, Mesta F. Oxidative stress as key player in severe acute respiratory 563 syndrome coronavirus (SARS-CoV) infection. Arch Med Res. 2020; 51:384-387

564 [36] Hamrahian AH, Fleseriu M; AACE adrenal scientific committee. Evaluation and 565 management of adrenal insufficiency in critically ill patients: disease state review. Endocr 566 Pract. 2017;23(6):716-725

567 [37] Mateos Moreno L, Palacios Garcia N, Estrada Garcia FJ. Adrenal insufficiency in 568 critical patients: new ethiopathogenic concepts and therapeutic implications. Endocrinol 569 Diabetes Nutr. 2017;64(10):557-563.

570 [38] Hamming I, Timens W, Bultuis MLC, Lely AT, Navis GJ, van Goor H. Tissue 571 distribution of ACE2 protein, the functional receptor for SARS coronavirus. A first step in 572 understanding SARS pathogenesis. J Pathol. 2004;203(2):631-637

573 [39] Ding YQ, Wang HJ, Shen H, Li ZG, Geng J, Han HX, Cai JJ, Li X, Kang W, Weng DS, 574 Lu YD, Yao KT. Study on etiology and pathology of severe acute respiratory syndrome. 575 Zhonghua Bing Li Xue Za Zhi. 2003;32(3):195-200

576 [40] Leow MKS, Kwek DSK, Ng AWK, Kaw GJL, Lee LSU. Hypocortisolism in survivors 577 of severe acute respiratory syndrome (SARS). Clin Endocrinol (Oxf).2005;63:197-202 
578 [41] Alzahrani AS, Mukhtar N, Aljomaiah A, Aljamei H, Barkhsh A, Alsudani N, Elsayed 579 T, Alrashidi N, Fadel R, Alqahtani E, Raef H, Butt MI, Sulaiman O. Endocr Pract. $580 \quad 2021 ; 27(2): 83-89$

581 [42] Pal R. COVID-19, hypothalamo-pituitary-adrenal axis and clinical implications. 582 Endocrine. 2020;68(2):251-252

583 [43] Coutinho AE, Chapman KE. The anti-inflammatory and immunosuppressive effects of 584 glucocorticoids, recent developments and mechanistic insights. Mol Cell Endocrinol. $585 \quad 2011 ; 335: 2-13$

586 [44] Van Der Velden VHJ. Glucocorticoids: mechanisms of action and anti-inflammatory 587 potential in asthma. Mediators inflamm.1998 (7):229-237

588 [45] Busillo JM, Azzam KM, Cidlowski JA. Glucocorticoids sensitize the innate immune 589 system through regulation of the NLRP3 inflammasome. J Biol Chem. 2011;286:38703$590 \quad 38713$

591 [46] Pinto A, Jacobsen M, Geoghegan PA, Cangelosi A, Cejudo ML, Tironi-Farinati C, 592 Goldstein J. Dexamethasone rescues neurovascular unit integrity from cell damage caused 593 by systemic administration of shiga toxin 2 and lipopolysaccharide in mice motor cortex. $594 \quad$ PLoS One 2013;8:e70020

595 [47] RECOVERY Collaborative Group, Horby P, Lim WS, Emberson JR, Mafham M, Bell 596 JL, Linsell L, et al. Dexamethasone in hospitalized patients with Covid-19- Preliminary 597 report. N Engl J Med. 2020 Jul 17. 
598 [48] Singh AK, Majumdar S, Singh R, Misra A. Role of corticosteroids in the management 599 of COVID-19: A systemic review and a clinician's perspective. Diabetes Metab Syndr. $600 \quad 2020 ; 14(5): 971-978$

601 [49] Selvaraj V, Dappah-Afriyie K, Finn A, Flanigan TP. Short-term dexamethasone in 602 SARS-CoV-2 patients. R I Med J (2013). 2020;103(6):39-43

603 [50] Ledford H. Coronavirus breakthrough: dexamethasone is first drug shown to save lives. 604 Nature. 2020;582(7813):469

605 [51] Isidori AM, Arnaldi G, Boscaro M, et al. COVID-19 infection and glucocorticoids: 606 update from the Italian Society of Endocrinology Expert Opinion on steroid replacement in 607 adrenal insufficiency. J Endocrinol Invest. 2020;43(8):1141-1147. doi:10.1007/s40618-020$608 \quad 01266-w$

609 [52]Villar J, Ferrando C, Martínez D, et al. Dexamethasone treatment for the acute res

610 piratory distress syndrome: a multicentre, randomised controlled trial. Lancet Respir Med. 611 2020;8(3):267-276. doi:10.1016/S2213-2600(19)30417-5.

612 [53] Russell CD, Millar JE, Baillie JK. Clinical evidence does not support corticosteroid 613 treatment for 2019-nCoV lung injury. Lancet. 2020;395(10223):473-475. 614 doi:10.1016/S0140-6736(20)30317-2.

615 [54] Lee N, Allen Chan KC, Hui DS. Effects of early corticosteroid treatment on plasma 616 SARS-associated Coronavirus RNA concentrations in adult patients. J Clin Virol. $617 \quad 2004 ; 31: 304-309$. 
618 [55] Erdó F, Bors LA, Farkas D, Bajza Á, Gizurarson S. Evaluation of intranasal delivery 619 route of drug administration for brain targeting. Brain Res Bull. 2018;143:155-170

620 [56] Meneses G, Cárdenas G, Espinosa A, et al. Sepsis: developing new alternatives to reduce 621 neuroinflammation and attenuate brain injury. Ann N Y Acad Sci. 2019;1437(1):43-56. 622 doi:10.1111/nyas.13985

623 [57] Espinosa A, Meneses G, Chavarría A, Mancilla R, Pedraza-Chaverri J, Fleury A, 624 Barcena B, Pérez Osorio IN, Besedovsky H, Arauz A, Fragoso G, Sciutto E. Intranasal 625 dexamethasone reduces mortality and brain damage in a mouse experimental ischemic stroke 626 model. Neurotherapeutics 2020 Jul 6. Doi:10.1007/s13311-020-00884-9

627 [58] Meneses G, Gevorkian G, Florentino A, et al. Intranasal delivery of dexamethasone 628 efficiently controls LPS-induced murine neuroinflammation. Clin Exp Immunol. 629 2017;190(3):304-314. doi:10.1111/cei.13018

630 [59] Rassy D, Bárcena B, Pérez-Osorio IN, et al. Intranasal Methylprednisolone Effectively 631 Reduces Neuroinflammation in Mice with Experimental Autoimmune Encephalitis. J 632 Neuropathol Exp Neurol. 2020;79(2):226-237.

633 [60] Zhang Y, Hu S, Wang J, Xue Z, Wang C, Wang N. Dexamethasone inhibits SARS634 CoV-2 spike pseudotyped virus viropexis by binding to ACE2. Virology 2021;554:83-88

635 [61] Finney LJ, Glaville N, Farne H, et al. Inhaled corticosteroids downregulate the SARS636 CoV-2 receptor ACE2 in COPD through suppression of type I interferon. BioRxiv 2020. 637 Doi:10.1101/202.06.13.149039 
638 [62] Wang T, Zhao Y, Fan F, Hu R, Jin X. Dexamethasone inhibits S. aureus-induced 639 neutrophils extracellular pathogen-killing mechanism, possibly through toll-like receptor 640 regulation. Front Immunol 2017:8:60. Doi:10.3389/fimmu.2017.00060.

641 [63] Zuo Y, Yalavarthi S, Shi H, Gockman K, Zuo M, Madison JA, et al. Neutrophils 642 extracellular traps (NETs) as markers of disease severity in COVID-19. medRxiv. $643 \quad 2020: 2020.04 .09 .20059626$

644 [64] Middleton EA, He XY, Denorme F, Campbell RA, Ng D, Salvatore SP et al.. 645 Neutrophils extracellular traps (NETs) contribute to immunothrombosis in COVID-19 acute 646 respiratory distress syndrome. Bloods 2020: blood.2020007008

647

648 


\section{Supplementary Files}

This is a list of supplementary files associated with this preprint. Click to download.

- SPIRITchecklist2021.docx 